\title{
DENSITY AND COVERAGE OF SEAGRASS ON DIFFERENT TYPE OF SEDIMENT AT PANDARATAN BEACH TAPANULI TENGAH REGENCY NORTH SUMATERA PROVINCE
}

\author{
Dea Lianov ${ }^{1^{*}}$, Efriyeldi ${ }^{2}$, Zulkifli $^{2}$ \\ ${ }^{1}$ Student of The Faculty of Fisheries And Marine Science University of Riau, Pekanbaru \\ ${ }^{2}$ Lecturer at the Faculty of Fisheries And Marine Science University Riau, Pekanbaru \\ *dealnv30@gmail.com
}

\begin{abstract}
Seagrass ecosystem is one of shallow sea ecosystems that plays an important role to maintain stability of the sea. Density and coverage of seagrass depend on characteristic of sediment, include mean size and the type of sediment. The purpose of this study was to find out how density and coverage of seagrass on different type of sediment at Pandaratan Beach Tapanuli Tengah Regency North Sumatera Province. This research was conducted in April 2019. From the results can be discovered that there are two species of seagrass that found in Pandaratan Beach, Cymodocea rotundata and Enhalus acoroides. In the type of muddy sand sediment has the heighest density of seagrass which is $309 \mathrm{ind} / \mathrm{m}^{2}$ and categorized into very tight. In the type of sandy gravel sediment has the lowest density of seagrass which is 49 ind $/ \mathrm{m}^{2}$ and categorized into very rare. And in the type of gravely sand sediment has the density of seagrass that is $234 \mathrm{ind} / \mathrm{m}^{2}$ and categorized into very tight. In the type of muddy sand sediment has the heighest coverage of seagrass which is $50.18 \%$ and categorized into good. In the type of sandy gravel sediment has the lowest coverage which is $17.72 \%$. And in the type of gravely sand sediment has the coverage of seagrass which is $26.95 \%$ and categorize into moderately.
\end{abstract}

Keywords: Seagrass, density of seagrass, coverage of seagrass, sediment

\section{PENDAHULUAN}

Ekosistem padang lamun merupakan salah satu dari ekosistem laut dangkal yang berperan penting dalam menjaga kestabilan perairan laut. Keberadaan ekosistem lamun di wilayah pesisir secara ekologis memberikan kontribusi yang cukup besar terutama berperan penting sebagai penyumbang nutrisi bagi kesuburan lingkungan perairan pesisir dan laut. Ekosistem lamun di daerah pesisir mempunyai produktivitas biologis yang tinggi, memiliki fungsi sebagai produsen primer, pendaur zat hara, stabilisator dasar perairan, perangkap sedimen serta penahan erosi.

Pantai Pandaratan adalah suatu pantai yang terletak di Kecamatan Sarudik Kabupaten Tapanuli Tengah. Pantai ini memiliki dua ekosistem di sekitarnya yaitu ekosistem mangrove dan ekosistem lamun, dimana ekosistem lamun di Pantai Pandaratan sangat luas. Pantai ini juga memiliki tiga tipe substrat yakni berpasir, berlumpur dan berbatu. Akan tetapi pantai ini lebih di dominasi oleh substrat pasir.

Belum adanya informasi mengenai kerapatan dan tutupan lamun berdasarkan perbedaan tipe sedimen maka perlu dilakukan penelitian ini untuk memberikan informasi mengenai kerapatan dan tutupan lamun pada tipe sedimen yang berbeda di Perairan Pantai Pandaratan. 
Tujuan dari penelitian ini adalah untuk mengetahui jenis lamun di Pantai Pandaratan, mengetahui kerapatan lamun berdasarkan perbedaan tipe sedimen dan mengetahui tutupan lamun berdasarkan perbedaan tipe sedimen.

\section{METODELOGI PENELITIAN}

\section{Waktu dan Tempat}

Penelitian ini dilaksanakan pada April 2019 di Pantai Pandaratan Kabupaten Tapanuli Tengah Provinsi Sumatera Utara untuk pengambilan data lapangan. Identifikasi sampel lamun dilaksanakan di Laboratorium Biologi Laut sedangkan analisis sampel sedimen dilaksanakan di Laboratorium Kimia Laut Jurusan Ilmu Kelautan Fakultas Perikanan dan Kelautan Universitas Riau.

\section{Metode Penelitian}

Metode yang dilakukan untuk kerapatan dan tutupan lamun adalah metode survei yaitu dengan cara mengumpulkan data di lapangan menggunakan transek kuadran, sedangkan pengambilan sampel sedimen di lapangan dianalisis di laboratorium.

\section{Prosedur Penelitian}

\section{Penentuan Lokasi Titik Sampling}

Penentuan titik sampling dilakukan dengan menggunakan metode purposive sampling. Lokasi penelitian akan dibagi atas 3 stasiun yang dianggap mewakili daerah penelitian yaitu stasiun 1 padang lamun di substrat pasir berlumpur, stasiun 2 padang lamun di substrat pasir berkerikil dan stasiun 3 padang lamun di substrat kerikil berpasir. Penetuan tipe sedimen dilakukan sebelum peletakan plot.

\section{Pengukuran Parameter Oseanografi}

Pengukuran parameter oseanografi dilakukan 3 (tiga) kali pengulangan pada masing-masing stasiun. Parameter oseanografi yang diukur antara lain suhu, salinitas, $\mathrm{pH}$, kecepatan arus dan kedalaman perairan.

\section{Kerapatan Lamun}

Pengambilan data kerapatan lamu dilakukan pada setiap stasiun dengan cara ditarik transek garis sepanjang padang lamun dari arah pantai ke arah laut. Setiap jarak yang disesuaikan dengan kondisi sebaran lamun dan tipe sedimen ditempatkan plot berukuran $50 \mathrm{~cm}$ x $50 \mathrm{~cm}$ untuk mengamati kerapatan lamun dengan menggunakan metode sampling sistematis (McKenzie, 2003).

Pengamatan kerapatan lamun dilakukan pada setiap jenis dengan cara menghitung jumlah tegakan masing-masing jenis di dalam plot. Kerapatan jenis lamun dihitung dengan mengunakan rumus:

$$
\mathrm{K}=\frac{\mathrm{N} i}{\mathrm{~A}}
$$

$$
\begin{aligned}
& \text { Keterangan: } \\
& \mathrm{K}=\text { Kerapatan jenis (tegakan } / \mathrm{m}^{2} \text { ) } \\
& \mathrm{Ni}=\text { Jumlah tegakan } \\
& \mathrm{A}=\text { Luas daerah sampling }\left(\mathrm{m}^{2}\right)
\end{aligned}
$$

Tabel 1. Skala Kondisi Padang Lamun Berdasarkan Kerapatan.

\begin{tabular}{ccc}
\hline Skala & Kerapatan $\left(\mathbf{i n d} / \mathbf{m}^{\mathbf{2}}\right)$ & Kondisi \\
\hline 5 & $\geq 175$ & Sangat rapat \\
4 & $125-175$ & Rapat \\
3 & $75-125$ & Agak rapat \\
2 & $25-75$ & Jarang \\
1 & $<25$ & Sangat jarang \\
\hline
\end{tabular}

Sumber: Braun-Blanquet dalam Gosari dan Haris (2012) 


\section{Tutupan Lamun}

Tabel 2. Skala Kondisi Padang Lamun berdasarkan Persentase Tutupan

\begin{tabular}{ccc}
\hline Skala & Persentase Tutupan & Kondisi \\
\hline 5 & $>75 \%$ & Sangat bagus \\
4 & $50-75 \%$ & Bagus \\
3 & $25-50 \%$ & Agak bagus \\
2 & $5-25 \%$ & Sedikit \\
1 & $<5 \%$ & Sangat sedikit \\
\hline
\end{tabular}

Sumber: Braun-Blanquet dalam Gasori dan Haris, 2012.

Untuk mengukur tutupan lamun dilakukan dengan cara petak contoh yang digunakan untuk pengambilan contoh berukuran $50 \mathrm{~cm}$ x $50 \mathrm{~cm}$ yang dibagi-bagi lagi menjadi $25 \mathrm{sub}$ petak, berukuran $10 \mathrm{~cm}$ x $10 \mathrm{~cm}$. Kemudian dicatat banyaknya masing-masing jenis pada tiap sub petak dan dimasukkan kedalam kelas kehadiran berdasarkan tabel berikut:

Tabel 3. Perhitungan Tutupan Lamun

\begin{tabular}{cccc}
\hline Kelas & Luas area penutupan & \% penutupan lamun & \% titik tengah $(\mathbf{M})$ \\
\hline 5 & $1 / 2-$ penuh & $50-100$ & 75 \\
4 & $1 / 4-1 / 2$ & $25-50$ & 37,5 \\
3 & $1 / 8-1 / 4$ & $12,5-25$ & 18,75 \\
2 & $1 / 16-1 / 8$ & $6,25-12,5$ & 9,38 \\
1 & $<1 / 16$ & $<6,25$ & 3,13 \\
0 & Tidak Ada & 0 & 0 \\
\hline
\end{tabular}

Sumber: KEPMEN-LH, 2004

Adapun penghitungan penutupan jenis lamun tertentu pada masing-masing petak dilakukan dengan menggunnakan rumus:

$$
C=\frac{\sum(M i \times f i)}{\sum f}
$$

Keterangan:

$\mathrm{C}=$ Persentase tutupan jenis lamun $i$

$\mathrm{Mi}=$ Persentase titik tengah dari kehadiran jenis lamun $i$

$f \quad=$ Banyaknya sub petak dimana kelas kehadiran jenis lamun $i$ sama

\section{Analisis Sampel Sedimen}

Penanganan sampel sedimen mengikuti prosedur yang merujuk pada (Rifardi, 2008), yaitu analisis ukuran butir sedimen untuk fraksi pasir dan kerikil digunakan metode pengayakan basah, untuk fraksi lumpur dianalisis dengan metode pipet. Untuk menggolongkan jenis sedimen dilakukan metode menurut Sheppard dalam
Rifardi (2008) dengan membagi suatu diagram rangkap tiga ke dalam kelas. Diagram Sheppard mengikuti konvensikonvensi semua diagram rangkap tiga.

\section{HASIL DAN PEMBAHASAN}

\section{Keadaan Umum Lokasi Penelitian}

Pantai Pandaratan terletak di

Kelurahan Pondok Batu, Kecamatan Sarudik, Kabupaten Tapanuli Tengah. Pantai yang berjarak sekitar satu kilometer dari dari kota Sibolga ini berpotensi sebagai objek wisata, selain memiliki pantai dengan hamparan pasir putih disekitar Pantai Pandaratan juga terdapat gua karang yang alami serta air terjun kecil. Pantai yang diakses dengan cara mendaki dan menuruni bukit ini masih belum mendapatkan perhatian khusus dari Pemerintah Tapanuli Tengah, terlihat dari belum adanya sarana dan prasarana yang mendukung potensi Pantai Pandaratan tersebut, serta akses menuju pantai yang rusak parah menjadi 
salah satu kendala utama pengunjung yang ingin berdatangan.

\section{Parameter Oseanografi}

Kondisi lingkungan perairan sangat mempengaruhi keberlangsungan hidup organisme seperti suhu, salinitas, $\mathrm{pH}$ dan kecepatan arus. Berdasarkan hasil penelitian parameter oseanografi di Pantai Pandaratan, dimana kondisi kualitas perairan di pantai tersebut masih bagus untuk mendukung kehidupan bagi organisme di dalamnya.

\section{Jenis dan Kerapatan Lamun}

Dalam penelitian ini pengamatan kerapatan dan tutupan lamun dibagi menjadi 3 (tiga) stasiun di Perairan Pantai
Pandaratan. Berdasarkan hasil pengamatan di lapangan diperoleh dua jenis lamun, yaitu Enhalus acroides dan Cymodocea rotundata.

Berdasarkan hasil penelitian, didapatkan kerapatan lamun pada tipe sedimen pasir berlumpur dari jenis Enhalus acoroides adalah $158 \mathrm{ind} / \mathrm{m}^{2}$ dan pada jenis Cymodocea rotundata adalah $151 \mathrm{ind} / \mathrm{m}^{2}$. Pada tipe sedimen kerikil berpasir kerapatan dari jenis Enhalus acoroides adalah 32 $\mathrm{ind} / \mathrm{m}^{2}$ dan jenis Cymodocea rotundata tidak ditemukan. Pada tipe sedimen pasir berkerikil kerapatan dari jenis Enhalus acoroides adalah $56 \mathrm{ind} / \mathrm{m}^{2}$ dan pada jenis Cymodocea rotundata adalah $187 \mathrm{ind} / \mathrm{m}^{2}$.

Tabel 4. Hasil Kerapatan Lamun di Perairan Pantai Pandaratan

\begin{tabular}{lccc}
\hline \multirow{2}{*}{ Tipe Sedimen } & \multicolumn{2}{c}{ Kerapatan Lamun (Ind/m2) } & \multirow{2}{*}{ Jumlah } \\
\cline { 2 - 3 } & Enhalus acoroides \pm SD & Cymodocea rotundata \pm SD & \\
\hline Pasir berlumpur & $158 \pm 91,65$ & $151 \pm 122,14$ & 309 \\
Kerikil berpasir & $32 \pm 17,85$ & - & 32 \\
Pasir berkerikil & $56 \pm 47,61$ & $187 \pm 61,92$ & 243 \\
Rata-rata & 82 & 113 & 194 \\
\hline
\end{tabular}

Keterangan: P.L $=$ Pasir berlumpur K.P $=$ Kerikil berpasir P.K $=$ Pasir berkerikil EA $=$ Enhalus acroides $\mathrm{CR}=$ Cymodocea rotundata

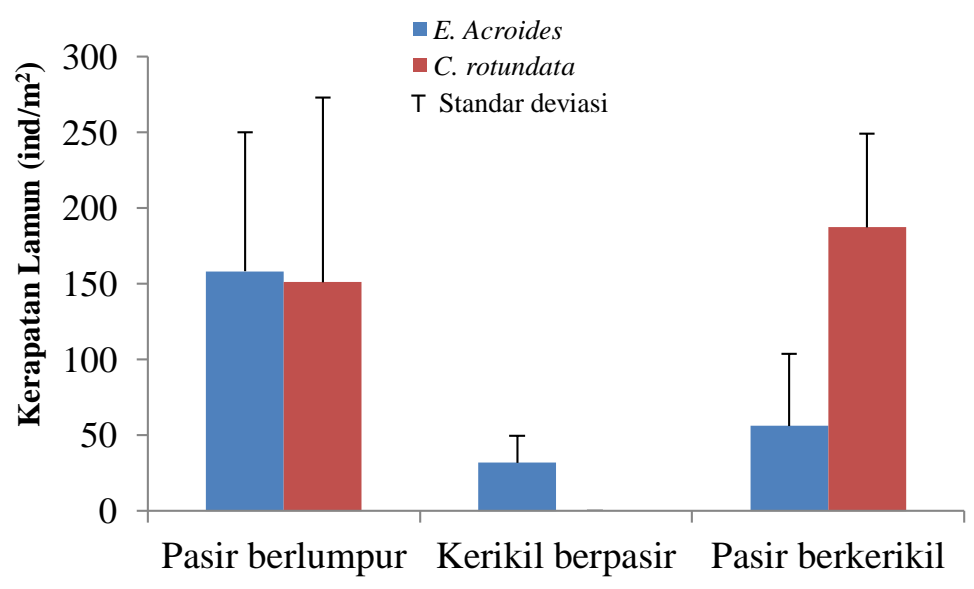

Tipe Sedimen

Gambar 1. Grafik Kerapatan Lamun di Perairan Pantai Pandaratan

Jenis Enhalus acoroides ditemukan pada semua tipe sedimen. Pada pasir berlumpur jenis Enhalus acoroides memiliki kerapatan tertinggi yaitu 158 $\mathrm{ind} / \mathrm{m}^{2}$. Menurut Feryatun et al (2012), Enhalus acoroides tumbuh dengan baik pada substrat pasir dan pasir berlumpur 
yang mendukung untuk kehidupan Enhalus acoroides. Kondisi morfologi pantai yang landai dan substrat pasir sangat mempengaruhi kerapatan dan pertumbuhan lamun Enhalus acoroides (Rahman et al., 2016).

Jenis Cymodocea rotundata memiliki nilai kerapatan tertinggi pada tipe sedimen pasir berkerikil yaitu $187 \mathrm{ind} / \mathrm{m}^{2}$. Cymodocea rotundata lebih dominan mendiami substrat yang berpasir dan substrat

yang terdiri dari pecahan karang. Hal ini sesuai dengan Sarfika (2012) yang menyatakan bahwa habitat lamun Cymodocea sp tumbuh pada substrat pasir berlumpur atau pasir dari pecahan karang pada daerah pasang surut. Serta pada tipe sedimen kerikil berpasir parameter oseanografinya seperti suhu, salinitas, $\mathrm{pH}$, kecepatan arus dan kedalaman perairan juga mendukung untuk pertumbuhan lamun.
Hasil uji one way ANOVA menunjukkan bahwa kerapatan lamun pada tipe sedimen yang berbeda adalah berbeda nyata $(p=0,00<0,05)$. Hasil uji lanjut LSD menunjukkan kerapatan lamun pada tipe sedimen pasir berlumpur, kerikil berpasir maupun pasir berkerikil adalah berbeda nyata. Hal ini sesuai dengan penelitian Suparno dalam Daeng (2018) bahwa kerapatan lamun tertinggi terdapat pada tekstur sedimen halus dan terendah terdapat pada tekstur sedimen kasar.

\section{Tutupan Lamun}

Dari hasil penelitian yang dilakukan pada 12 April 2019 di Pantai Pandaratan Kabupaten Tapanuli Tengah, didapatakan hasil persentase tutupan lamun pada tipe sedimen pasir berlumpur adalah 50,18\%, persentase tutupan lamun pada tipe sedimen kerikil berpasir adalah $17,72 \%$, dan persentase tutupan lamun pada tipe sedimen pasir berkerikil adalah $26,95 \%$ dengan ratarata persentase tutupan lamun satu lokasi/pantai adalah 31,62\%.

Tabel 9. Hasil Tutupan Lamun di Perairan Pantai Pandaratan.

\begin{tabular}{lcc}
\hline Tipe Sedimen & Tutupan Lamun $(\%) \pm$ Standar Deviasi & Kondisi \\
\hline Pasir berlumpur & $50,18 \pm 12,24$ & Bagus \\
Kerikil berpasir & $17,72 \pm 16,77$ & Sedikit \\
Pasir berkerikil & $26,95 \pm 8,63$ & Agak Bagus \\
Rata-rata & 31,62 & Agak Bagus \\
\hline
\end{tabular}

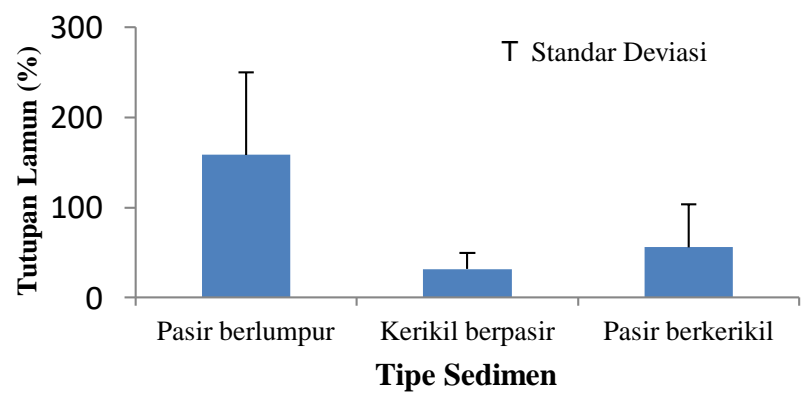

Gambar 2. Grafik Persen Tutupan Lamun

Nilai tutupan lamun tertinggi yaitu pada tipe sedimen pasir berlumpur dengan nilai $50,18 \%$ dan dikategorikan dengan kondisi bagus, selain tipe sedimen pasir berlumpur yang sangat mendukung pertumbuhan lamun kondisi parameter oseanografi pada stasiun I juga masih baik untuk pertumbuhan lamun, baik dari suhu, salinitas, pH, kecepatan arus maupun 
kedalaman perairan. Sementara nilai tutupan terendah pada tipe sedimen kerikil berpasir yaitu $19,59 \%$ yang dikategorikan dalam kondisi sedikit. Selain tipe sedimen yang terlalu kasar, tingginya kadar salinitas pada stasiun II ini merupakan salah satu faktor rendahnya tutupan lamun, hal ini menurut Hasanudin (2013) salah satu faktor yang menyebabkan kerusakan lamun adalah meningkatnya salinitas akibat kurangnya suplai air tawar dari daratan. Pada tipe sedimen pasir berkerikil ditutupi lamun dengan nilai $26,95 \%$ yaitu termasuk kategori agak bagus.

Hasil uji one way ANOVA menunjukkan tutupan lamun pada semua tipe sedimen adalah berbeda nyata $(\mathrm{p}=$ $0,00<0,05)$. Hasil uji lanjut LSD menunjukkan tutupan lamun pada tipe sedimen pasir berlumpur sangat berbeda nyata dengan tipe sedimen kerikil berpasir dan pasir berkerikil, sementara tutupan lamun pada tipe sedimen kerikil berpasir tidak ada perbedaan yang nyata dengan pasir berkerikil.

Menurut Kasim dalam Sari dan Dahlan (2015), persentase penutupan lamun menggambarkan luas lamun yang menutupi suatu perairan, dimana tinggi penutupan tidak selamanya linier dengan tingginya kerapatan jenis. Hal ini dipengaruhi pengamatan penutupan yang diamati adalah helaian daun, sedangkan kerapatan yang dilihat adalah jumlah tegakan lamun. Makin lebar ukuran panjang dan lebar daun lamun maka semakin besar menutupi substrat dasar perairan.

\section{KESIMPULAN DAN SARAN}

\section{Kesimpulan}

$\mathrm{H}_{1 \text { (Kerapatan Lamun) }}$ dan $\mathrm{H}_{1 \text { (Tutupan Lamun) }}$ diterima yaitu terdapat perbedaan kerapatan dan tutupan lamun pada tipe sedimen yang berbeda dan dapat disimpulkan sebagai berikut:

1. Pada kawasan Pantai Pandaratan ditemukan 2 jenis lamun yaitu Cymodocea rotundata dan Enhalus acoroides

2. Adanya perbedaan nilai kerapatan lamun pada tipe sedimen yang berbeda. Pada tipe sedimen pasir berlumpur memiliki kerapatan tertinggi yang tergolong sangat rapat dan padi sedimen kerikil berpasir memilik kerapatan terendah yang tergolon rapat.

3. Adanya perbedaan nilai tutupan lamun pada tipe sedimen yang berbeda. Pada tipe sedimen pasir berlumpur memiliki nilai tutupan tertinggi dan dikategorikan bagus dan pada tipe sedimen kerikil berpasir memiliki nilai tutupan terendah tergolong kategori sedikit. Maka, kerapatan dan tutupan lamun tertinggi pada tipe sedimen pasir berlumpur dan terendah pada tipe sedimen kerikil berpasir.

\section{Saran}

Perlunya dilakukan penelitian lanjutan untuk mengetahui bagaimana kerapatan maupun tutupan lamun pada karakteristik sedimen yang lebih rinci, kandungan nutrien perairan serta parameter lain terhadap kerapatan dan tutupan lamun untuk mengetahui informasi yang lebih signifikan serta sebagai informasi terbaru dibidang perikanan dan kelautan.

\section{DAFTAR PUSTAKA}

1. Braun-Blanquet, J. (1965). Plant Sociology: The Study of Plant Communities, (Trans. rev. and ed. by C.D. Fuller and H.S. Conard), Hafner, London.

2. Daeng, B. (2018). Keterkaitan Jenis dan Kerapatan Lamun dengan Tekstur Sedimen di Dusun Bringkassi Desa Sapanang Kecamatan Binamu Kabupaten Jeneponto. [Skripsi]. Universitas Hasanuddin. Makassar. 
3. Feryatun, F., B. Hendrarto, dan N. Widyorini. (2012). Kerapatan dan Distribusi Lamun Berdasarkan Zona Kegiatan yang Berbeda di Perairan Pulau Pramuka Kepulauan Seribu. Journal of Management of Aquatic Resources, Volume 8 Pages 1-7.

4. Hasanudin, R. (2013). Hubungan antara Kerapatan dan Morfometrik Lamun Enhalus acroides dengan Substrat dan Nutrien di Pulau Sarappo Lompo Kab. Pangkep. Universitas Hassanudin. Makassar.

5. KEPMENLH. (2004). Daftar Peraturan Perundangan Lingkungan Hidup. KepMen LH Nomor 200 Tahun 2004 Tentang Kriteria Baku Kerusakan dan Pedoman Penentuan Status Padang Lamun. Jakarta.

6. McKenzie, LJ. (2003). Guidelines for The Rapid Assessment and Mapping of Tropical Seagrass Habitats. The State of Queensland. Department of Primary Industries.

7. Rahman, A. A., A. I. Nur, dan M. Ramli. (2016). Studi Laju Pertumbuhan Lamun Enhalus acoroides di Perairan Pantai Desa Tanjung Tiram Kabupaten Konawe Selatan. Sapa Laut Volume 1(1) Pages 10-16.

8. Rifardi. (2008). Ekologi Sedimen Modern. UR Press. Pekanbaru.

9. Sarfika, M. (2012). Pertumbuhan Dan Produksi Lamun Cymodocea Rotundata Dan Cymodocea Serrulata di Pulau Pramuka dan Pulau Panggang, Kepulauan Seribu, DKI Jakarta. Fakultas Perikanan dan Ilmu Kelautan, Insitut Pertanian Bogor, Bogor.

10. Sari. A. dan Dahlan. (2015). Komposisi Jenis dan Tutupan Lamun di Perairan Teluk Yos Sudarso Koto Jayapura. The Journal of Fisheries Development, Volume 2(3) pages 1-8. 